\title{
RESULTS OF MONOCULAR SURGERY UNDER PERIBULBAR ANESTHESIA FOR LARGE-ANGLE HORIZONTAL STRABISMUS
}

\author{
Tatiana Millán, Keila Monteiro de Carvalho, Nilza Minguini
}

doi: 10.1590/S1807-59322009000400006

Millán T, de Carvalho KM, Minguini N. Results of monocular surgery under peribulbar anesthesia for large-angle horizontal strabismus. Clinics. 2009;64(4):303-8

OBJECTIVE: To evaluate the results of monocular surgery under peribulbar anesthesia for large-angle horizontal strabismus. INTRODUCTION: Monocular surgery may preserve some muscles if a repeat operation is required, may help to avoid the exposure of the dominant eye to the inherent risks of a surgical procedure and may reduce surgical time.

METHODS: We evaluated ninety-two consecutive patients who underwent monocular surgery under peribulbar anesthesia for large-angle horizontal strabismus (angle of 40 prism diopters or greater). Patients were divided into group 1- esotropia and group 2 -exotropia. The postoperative follow-up was at 6 months, when the residual deviation was evaluated. In cases of residual deviations of over 15 PD (prism diopter), a second procedure was indicated.

RESULTS: In all patients with preoperative deviations up to 60 PD, residual deviations were under 15 PD. Some patients with preoperative deviations of 65 PD (two in group 1 and four in group 2) and all patients with deviations over 65 PD had residual deviations over $15 \mathrm{PD}$. The 13 patients who underwent a second procedure experienced successful outcomes. Our ROC curve analysis showed that the cutoff point for obtaining a successful surgical result was 62.5 PD. No patient presented with a major limitation in respect of ocular movement.

CONCLUSIONS: Monocular surgery under peribulbar anesthesia can be an alternative for horizontal large-angle strabismus given deviations of up to 60 PD. Monocular surgery did not result in successful outcomes for deviations of over 65 PD.

KEYWORDS: Local Anesthesia; Strabismus/surgery; Ophthalmology; Surgical procedures; Operative; Ocular motility disorders.

\section{INTRODUCTION}

Binocular surgery is the most commonly used approach for surgical treatment of large-angle horizontal strabismus involving three or four horizontal rectus muscles. This procedure is widely used because it avoids significant limitations of ocular movement, which could occur in surgeries of greater magnitude. ${ }^{1-5}$ However, monocular surgery has many advantages, such as preserving some muscles if a repeat operation is required, avoiding the exposure of the dominant eye to the inherent risks of a

Ophthalmology Department, UNICAMP - Campinas/SP, Brazil. Email: tatimillan@yahoo.com.br Tel.: 55543223.1376

Received for publication on October 26,2008

Accepted for publication on December 26, 2008 surgical procedure and reducing surgical time. ${ }^{6-10}$

Furthermore, a monocular procedure can be performed in adults under peribulbar anesthesia, which is associated with decreased morbidity and mortality when compared with general anesthesia, and also offers swifter recovery and lower incidence rates of nausea and vomiting. ${ }^{11-19}$

The aim of this study was to evaluate the results of monocular surgery under peribulbar anesthesia for largeangle horizontal strabismus.

\section{METHODS}

\section{Subjects}

We evaluated the medical records of 92 consecutive patients who underwent monocular surgery under peribulbar anesthesia after January 2004 at the Department of Ophthalmology, 
University of Campinas (Campinas, SP, Brazil).

The inclusion criteria were:

- Large-angle strabismus: defined, in this study, as an angle of deviation of 40 prism diopters (PD) or greater;

- Primary strabismus, excluding all cases of paretic, restrictive or consecutive strabismus. Patients who had previously been administered botulinum toxin A to treat strabismus were also excluded.

- Horizontal strabismus (esotropia or exotropia), excluding any cases with associated vertical deviation.

- Follow-up data lasting at least 6 months.

\section{Procedures}

1) Complete ophthalmologic examination (best-corrected visual acuity measurement, biomicroscopy, tonometry and indirect ophthalmoscopy).

\section{2) Measurement of angle of deviation}

The angle of strabismus was measured in prism diopters (PD), with the best optic correction, in all positions, for both distance and near vision. For patients with good bilateral visual acuity, this parameter was measured by the prism and cover test using a suitable fixation target. Patients with poor vision or profound amblyopia were submitted to Krinsky measurement, based on the corneal reflex. ${ }^{20-22}$

After evaluation of strabismus, the subjects were divided into group 1 (patients with esotropia) and group 2 (patients with exotropia).

\section{3) Surgical planning and surgery}

The surgeries consisted of recession and resection and are described in Table 1 (group 1) and Table 2 (group 2). All patients underwent monocular surgeries in the nondominant eye.

A successful result was defined by a postoperative angle of 15 PD or less.

\section{4) Anesthesia}

Peribulbar anesthesia was performed by the ocular surgeon, and all patients received $5 \mathrm{mg}$ of diazepam orally, thirty minutes before anesthesia. An intravenous line, oxygen nasal cannula, cardiac monitoring and continuous pulse oximetry were employed. The local anesthetic consisted of $0.5 \%$ bupivacaine without epinephrine and $2 \%$ lidocaine with epinephrine.

\section{5) Follow-up}

Patients were examined at least on the first, seventh and thirtieth days and three and six months after surgery. Measurements of angles of deviation were recorded during all visits, but the data considered in this study were from the sixth postoperative month only.

\section{6) Second surgical procedure}

In cases of residual deviations of over 15 PD in the sixth month, a second procedure in the dominant eye was indicated, and the follow-up continued until at least six months after the second surgery. All patients accepted the

Table 1 - Characteristics of group 1 (esotropia)

\begin{tabular}{ccccc}
\hline $\begin{array}{c}\text { Preoperative deviation } \\
\text { (PD) }\end{array}$ & $\mathrm{N}^{\mathrm{o}}$ & $\begin{array}{c}\text { Age } * \\
\text { (years) }\end{array}$ & \multicolumn{1}{c}{$\begin{array}{c}\text { Surgical procedure } \\
\text { Postoperative Deviation * } \\
\text { (PD) }\end{array}$} \\
\hline 40 & 7 & $27.14 \pm 14.03$ & RC 5mm MR + RS 7mm LR & $7.71 \pm 3.73$ \\
45 & 9 & $24.11 \pm 6.95$ & RC 6mm MR + RS 7mm LR & $5.11 \pm 3.14$ \\
50 & 5 & $28 \pm 8.72$ & RC 6mm MR + RS 8mm LR & $6 \pm 3.74$ \\
55 & 1 & 21 & RC 6mm MR + RS 8mm LR & 5 \\
60 & 4 & RC 6mm MR + RS 9mm LR & $8,5 \pm 1,91$ \\
65 & 3 & $21.75 \pm 5.38$ & RC 6mm MR + RS 9mm LR & $18.33 \pm 2.89$ \\
70 & 5 & $22.67 \pm 1.53$ & RC 6mm MR + RS 9mm LR & $28 \pm 6,71$ \\
75 & 3 & $23.8 \pm 10.26$ & RC 6mm MR + RS 9mm LR & $28.33 \pm 5.77$ \\
80 & 3 & $29.67 \pm 14.36$ & RC 6mm MR + RS 9mm LR & $35 \pm 0$ \\
80 & 1 & $36.33 \pm 17.93$ & RC 7mm MR + RS 9mm LR & 30 \\
90 & 1 & 19 & RC 8mm MR + RS 9mm LR & 35 \\
95 & 1 & 22 & RC 8mm MR + RS 9mm LR & 35 \\
100 & 1 & 31 & & 55
\end{tabular}

* Mean \pm standard deviation; $\mathrm{N}^{\mathrm{o}}$ : number of patients; PD: prism diopter; RC: recession; RS: resection; MR: medial rectus; LR: lateral rectus; mm: millimeter 
Table 2 - Characteristics of group 2 (exotropia)

\begin{tabular}{lcccc}
\hline Preoperative Deviation (PD) & $\mathrm{N}^{\mathrm{r}}$ & Age * (years) & Surgical procedure & Postoperative Deviation *(PD) \\
\hline 40 & 9 & $31.44 \pm 10.92$ & RC 7mm LR + RS 7mm MR & $6.22 \pm 1.85$ \\
45 & 6 & $29.67 \pm 7.97$ & RC 7mm LR + RS 7mm MR & $8.67 \pm 1.63$ \\
50 & 8 & $34 \pm 8.75$ & RC 8mm LR + RS 7mm MR & $6.37 \pm 4.40$ \\
55 & 2 & $51 \pm 9.89$ & RC 8mm LR + RS 8mm MR & $10 \pm 0$ \\
60 & 10 & $28 \pm 8.94$ & RC 8mm LR + RS 8mm MR & $9.9 \pm 5.52$ \\
65 & 3 & $49.67 \pm 12.22$ & RC 8mm LR + RS 8mm MR & $26.67 \pm 2.89$ \\
65 & 6 & $29.17 \pm 7.14$ & RC 9mm LR + RS 8mm MR & $11.67 \pm 4.08$ \\
70 & 1 & 36 & RC 9mm LR + RS 8mm MR & 25 \\
75 & 1 & 44 & RC 9mm LR + RS 8mm MR & 20 \\
80 & 2 & $35 \pm 8.48$ & & $30 \pm 0$ \\
\hline $\mathbf{5 4 . 7 9} \pm \mathbf{1 1 . 1 5 *}$ & $\mathbf{4 8}$ & $\mathbf{3 2 . 5 4} \pm \mathbf{9 . 9 3 *}$ & & $\mathbf{1 1 . 1 0 \pm 7 . 5 9 *}$ \\
\hline
\end{tabular}

* Mean \pm standard deviation, $\mathrm{N}^{\mathrm{o}}$ : number of patients, PD: prism diopter, RC: recession, RS: resection, MR: medial rectus, LR: lateral rectus, mm: millimeter

conditions when informed about the surgery and possible need for a second surgery.

\section{Data analysis}

The data were analyzed using the Mann-Whitney test for comparison of age and preoperative and postoperative angles of deviation between the groups; repeated-measures ANOVA (analysis of variance) for preoperative and postoperative comparisons; and ANCOVA's (analysis of covariance) to adjust for covariates of age and type of deviation (esotropia or exotropia). The ROC curve (receiver operating characteristic) was used to define the cutoff point of preoperative angle of deviation for a successful outcome. A $\mathrm{P}$ value of $<0.05$ was considered statistically significant. The statistical analysis was performed using the SAS System for Windows (Statistical
Analysis System), version 8.01, 1999-2000.

This study was approved by the Research Ethics Committee of the Faculty of Medical Sciences - University of Campinas, Campinas/SP, Brazil.

\section{RESULTS}

Forty-four patients had esotropia (group 1) and fortyeight had exotropia (group 2). The patients' ages, as well as other data, such as preoperative angles of deviation, surgical procedures and postoperative deviations are shown in Tables 1 (patients with esotropia) and 2 (patients with exotropia).

All patients with preoperative deviation of up to $60 \mathrm{PD}$ in both groups underwent successful surgeries (postoperative deviation of $15 \mathrm{PD}$ or less in the sixth postoperative month). In patients with $65 \mathrm{PD}$ preoperative deviations, one of three

Table 3 - Group 1 patients (esotropia) who underwent a second procedure

\begin{tabular}{lcccc}
\hline Patient $\mathrm{N}^{\mathbf{2}}$ & Age (years) & $\begin{array}{c}\text { Deviation after first procedure } \\
\text { (prism diopter) }\end{array}$ & Second surgical procedure & $\begin{array}{c}\text { Deviation after second } \\
\text { procedure (prism diopter) }\end{array}$ \\
\hline 1 & 18 & $\mathbf{2 5}$ & RC 4 mm MR + RS 5mm LR & $\mathbf{6}$ \\
2 & 20 & $\mathbf{3 5}$ & RC 5 mm MR + RS 6mm LR & $\mathbf{1 0}$ \\
3 & 21 & $\mathbf{3 5}$ & RC 5 mm MR + RS 7mm LR & $\mathbf{1 0}$ \\
4 & 42 & $\mathbf{2 0}$ & RC 6 mm MR & $\mathbf{2}$ \\
5 & 24 & $\mathbf{3 5}$ & RC 5 mm MR + RS 7mm LR & $\mathbf{8}$ \\
6 & 25 & $\mathbf{3 5}$ & RC 5 mm MR + RS 7mm LR & $\mathbf{5}$ \\
7 & 57 & $\mathbf{3 5}$ & RC 5 mm MR + RS 7mm LR & $\mathbf{6}$ \\
8 & 27 & $\mathbf{3 5}$ & RC 6 mm MR + RS 9mm LR & $\mathbf{0}$ \\
9 & 31 & $\mathbf{5 5}$ & & $\mathbf{1 0}$ \\
\hline Mean & 29.44 & 34.44 & & 6.33 \\
\hline
\end{tabular}

RC: recession, RS: resection, MR: medial rectus, $L R$ : lateral rectus, mm: millimeter. 
Table 4 - Group 2 patients (exotropia) who underwent a second procedure

\begin{tabular}{lcclc}
\hline Patient $N^{\circ}$ & Age (years) & $\begin{array}{c}\text { Deviation after first procedure } \\
\text { (prism diopter) }\end{array}$ & Second surgical procedure & $\begin{array}{c}\text { Deviation after second } \\
\text { procedure (prism diopter) }\end{array}$ \\
\hline 1 & 30 & $\mathbf{2 5}$ & RT RL 5mm RS RM 5mm & $\mathbf{4}$ \\
2 & 54 & $\mathbf{3 0}$ & RT RL 7mm RS RM 6mm & $\mathbf{0}$ \\
3 & 38 & $\mathbf{2 5}$ & RT RL 5mm RS RM 5mm & $\mathbf{- 4}$ \\
4 & 36 & $\mathbf{2 5}$ & RT RL 4mm RS RM 5mm & $\mathbf{5}$ \\
\hline Mean & 39.5 & 26 & & 1.25 \\
\hline
\end{tabular}

RC: recession, RS: resection, MR: medial rectus, LR: lateral rectus, mm: millimeter.

patients in group 1 and five of nine patients in group 2 underwent successful surgeries. All patients with deviations over 65 PD presented with a residual deviation of over 15 $\mathrm{PD}$, which ranged from 20 to $55 \mathrm{PD}$ in group 1, and from 20 to $30 \mathrm{PD}$ in group 2.

A total of 25 patients exhibited residual deviations of over $15 \mathrm{PD}$, but only thirteen (52\%) elected to undergo a second procedure, which turned out to be successful in all cases. The angle of deviation after the first surgical procedure, the second surgical procedure and the postoperative deviation six months after surgery are shown in Tables 3 (patients with esotropia) and 4 (patients with exotropia).

No patient presented with severe limitations in respect of ocular movement. However, all patients who underwent the 8 $\mathrm{mm}$ recession of medial rectus in group 1 experienced some degree of limitation in ocular movement. In group 2, 6 of the 10 patients submitted to $9 \mathrm{~mm}$ recession of lateral rectus presented with some degree of limited ocular movement.

There were no complications from surgery or anesthesia in either group.

Based on the Mann-Whitney test, there was a statistically significant difference in age (group 1 was younger, $\mathrm{p}=0.026$ ), but no difference in the preoperative angle of deviation $(\mathrm{p}=0.0512)$, the magnitude of surgical correction $(\mathrm{p}=0.6602)$ and the postoperative results $(\mathrm{p}=0.320)$. The preoperative deviations were significantly greater than the postoperative in both groups (ANOVA, $\mathrm{p}<0.0001$ ). With ANCOVA, our analyses were adjusted for the variables of age and type of strabismus (esotropia or exotropia), and there were no statistically significant differences $(\mathrm{p}=0.217)$.

The Spearman's rank correlation coefficient showed no correlation between age and postoperative deviation $(\mathrm{r}=-0.13360, \mathrm{p}=0.3047)$. There was a moderate correlation between preoperative and postoperative deviations $(\mathrm{r}=$ $0.43703, \mathrm{p}=0.0004)$.

The ROC analysis (Figure 1) showed that the cutoff point of the preoperative angle for obtaining a successful surgery result was $62.5 \mathrm{PD}$. The sensitivity and specificity using this cutoff point, the estimated area under ROC curve and the 95\% confidence interval are shown in Figure 1.
ROC Curve

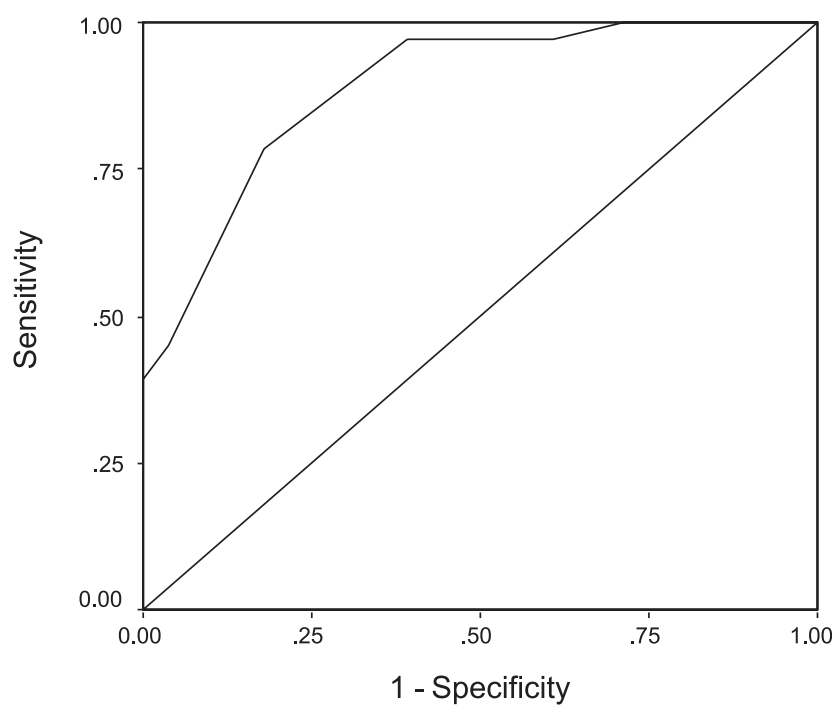

Area under ROC curve $=0.891 ; 95 \% \mathrm{CI}=0.812$ to $0.970 ; \mathrm{p}<0.001$ Sensitivity $=78.8 \%$; Specificity $=82.1 \%$; Accuracy $=80.3 \% ; \mathrm{n}=92$ Optimal cutoff point selected $\leq 62.5$

Figure 1 - ROC Curve

\section{DISCUSSION}

Most studies of surgical procedures in large-angle horizontal strabismus were conducted in congenital esotropia. Several authors reported high rates of success, from 70 to $91 \%$, in large-angle congenital esotropia with large medial rectus recessions, and no significant adduction limitations. ${ }^{23-31}$ More recently, Vroman et al. and PrietoDiaz and Souza-Dias also suggested that bilateral medial rectus recession was the preferred treatment for large-angle congenital esotropia. ${ }^{30,31}$ Other studies, however, suggest that interventions involving three or four muscles are more effective and avoid convergence injuries. ${ }^{3-5}$

Several studies of large-angle exotropia have reported success rates ranging from $72 \%$ to $80 \%$ in bilateral lateral rectus recessions, without significant abduction limitations. ${ }^{6-10}$ Berland et al. reported a success rate of $80 \%$ with a 8 to $9 \mathrm{~mm}$ bilateral lateral rectus recession, but with 
abduction limitations in $30 \%$ of the 24 patients studied. ${ }^{6}$ Bracamontes et al. supported bilateral surgery in large-angle exotropias in patients with low vision in one or both eyes, because the relapse rate is higher with monocular surgery. ${ }^{32}$ However, Currie et al. suggested that interventions involving three or four muscles in large-angle exotropias are more effective than surgery involving only two muscles. ${ }^{2}$

The ROC analysis was used to define the cutoff point of the preoperative deviation, in order to achieve a successful result ( $\leq 62.5 \mathrm{PD}$ ) corresponding to the area under the curve with a $95 \%$ confidence interval. We identified no differences between groups 1 and 2 because the ANCOVA test did not show any influence of the type of strabismus on the postoperative result. There have been no other studies to date that have estimated a cutoff point in terms of the preoperative deviation needed to achieve a successful outcome in monocular surgery for large-angle strabismus.

Our results show that, after the second procedure, the residual deviations achieved results of 10 PD or less, suggesting that strabismus with a preoperative angle of deviation of 65 PD or greater (Tables 3 and 4) exhibited the best outcomes following binocular approaches.

Ocular movement may be limited in major recessions and in patients with good bilateral visual acuity; these limitations may cause damage in terms of the convergence amplitude. Most authors recommend not exceeding $7 \mathrm{~mm}$ medial rectus recession and $8 \mathrm{~mm}$ lateral rectus recession to avoid ocular movement limitations. In this study, only $8 \mathrm{~mm}$ medial rectus recession in group 1 and $9 \mathrm{~mm}$ lateral rectus recession in group 2 were associated with some degree of limitation. These results confirm the conclusions from other studies, all of which recommend avoiding large recessions. ${ }^{29,31}$

The effects of peribulbar anesthesia in terms of surgical results have been previously reported by our group. Our published studies compared the postoperative results of strabismus surgery performed under peribulbar and general anesthesia and confirmed that the type of anesthesia used did not impact the surgical results. ${ }^{33,34}$ The disadvantages of this type of anesthesia include reduced globe mobility, which causes problems in analyzing passive stiffness. Ocular complications of peribulbar anesthesia include globe perforation, retrobulbar hemorrhage, ptosis, optic nerve injury and central retinal artery occlusion ${ }^{35,36}$ However, these complications are rare and occurred only in $0.006 \%$ of 16,224 consecutive peribulbar block cases in a multicenter study. ${ }^{36}$

\section{CONCLUSIONS}

Monocular surgery under peribulbar anesthesia can be a viable alternative for large-angle horizontal strabismus for patients who present deviations of up to $60 \mathrm{PD}$. Monocular surgery did not result in acceptable outcomes for deviations of over $65 \mathrm{PD}$.

\section{REFERENCES}

1. Amitava AK, Goswami AK, Mishra A. Large-angle strabismus and primary true muscle transplantation. J Pediatr Ophthalmol Strabismus. 2005;42(4):211-5.

2. Currie ZI, Shipman T, Burke JP. Surgical correctuson of large-angle exotropia in adults. Eye. 2003;17(3):334-9.

3. Forrest MP, Finnigan S, Finnigan S, Gole GA. Three horizontal muscle squint surgery for large angle infantile esotropia. Clin Experiment Ophthalmol. 2003; 31(6):509-16.

4. Lee D, Dyer J. Bilateral medial rectus muscle recession and lateral rectus resection in the treatment of congenital esotropia. Am J Ophthalmol. 1983;95:528-35.

5. Scott WE, Reese PD, Hirsh CR, Flabetich CA. Surgery for large - angle congenital esotropia: two vs. three and four horizontal muscles. Arch Ophthalmol. 1986;104:374-7.

6. Berland JE, Wilson ME, Saunders RB. Results of large (8-9mm) bilateral lateral rectus muscle recessions for exotropia. Binocul Vis Strabismus Q. 1998;13(2):97-104.

7. Celebi S, Kukner AS. Large bilateral lateral rectus recession in large angle divergence excess exotropia. Eur J Ophthalmol. 2001;11(1):68
8. Livir-Rallatos G, Gunton KB, Calhoun JH. Surgical results in large-angle exotropia. J AAPOS. 2002;6(2):77-80.

9. Rayner JW, Jampolsky A. Management of adult patients with large angle exotropia and amblyopia. Ann Ophthamol. 1973;5:95-9.

10. Schwartz RL, Calhoun JH. Surgery of large angle exotropia. J Pediatr Ophthalmol Strabismus. 1980;17(6):359-63.

11. Cheng KP, Larson CE, Biglan AW, D'Antonio JA. A prospective, Randomized Controlled Comparison of Retrobulbar and General Anesthesia for Strabismus Surgery. Ophthalmic Surgery. 1992;23(9):58590.

12. Ripart J, Lefrant JY, de La Coussaye JE, Prat-Pradal D, Vivien B, Eledjam JJ. Peribulbar versus retrobulbar anesthesia for ophthalmic surgery. Anesthesiology. 2001; 94(1):56-62.

13. Greenberg MF, Pollard ZF. Adult Strabismus Surgery Under Propofol Sedation With Local Versus General Anesthesia. J AAPOS. 2003; 7:11620.

14. Lavrich JB, Nelson LB. Local anaesthesia for strabismus surgery. Ophthalmol Clin North Am. 1992; 5:131-41.

15. Wang HS. Peribulbar anesthesia for ophthalmic procedures. J Cataract Refract Surg. 1988; 14:441-3. 
16. Szmyd SM, Nelson LB, Calhoun JH, Harley RD. Retrobulbar Anesthesia in Strabismus Surgery. Arch Ophthalmol. 1984;102(9):1325-7.

17. Fry RA, Walker M. An audit of postoperative nausea and vomiting (PONV) following strabismus surgery. Anaesth Intens Care. 1998;26:700.

18. Lawler RA, Larson C, Rudy T, Beglan AW. The comparative incidence of post-operative vomiting in adults and teen unilateral strabismus surgeries performed under general anesthesia or retrobulbar blockade. Anesthesiology. 1988;69(3A): 370.

19. Sanders JR, Nelson LB, Deutsch JA. Peribulbar Anesthesia for Strabismus Surgery. Am J Ophthalmol. 1990;109(6):705-8.

20. Choi RY, Kushner BJ. The accuracy of experienced strabismologists using the Hirschberg and Krimsky tests. Ophthalmology. 1998;105(7):1301-

21. Johnson R, Wynn S, Coffey B. Influences of examiner position and effective prism power on nearpoint alternate cover test. Optometry. 2004;75(8):496-502.

22. Parks MM. Atlas of Strabismus Surgery. Philadelphia: Harper \& Row;1983.

23. Szmyd SM, Nelson LB, Calhoun JH, Spratt C. Large bimedial rectus recession in congenital esotropia. Br J Ophthalmol. 1985;69(4):2714.

24. Grin TR, Nelson LB. Large unilateral medial rectus recession for treatment of esotropia. Br J Ophthalmol. 1987;71:377-9.

25. Keenan Jm, Willshaw HE. The outcome of strabismus surgery in childhood esotropia. Eye. 1993;7(Pt3):341-3.

26. Richler M, Barsoum-Homsy M. Bimedial rectus recession measured from the limbus for congenital esotropia. Can J Ophthalmol. 1989;24(7):304-7.
27. Weakley DR, Stager DR, Everett ME. Seven millimeter medial rectus recession in infantile esotropia. J Pediatr Ophthalmol Strabismus. 1991;28:113-5.

28. Willshaw HE, Mashoudi N, Powell S. Augmented medial rectus recession in the management of esotropia. Br J Ophthalmol. 1996;70:840-3.

29. Damanakis AG, Arvandis PG, Ladar ID, Theodossiadis GP. $8 \mathrm{~mm}$ bimedial rectus recession in infantile esotropia of 80-90 prism diopters. Br J Ophthalmol. 1994; 78(11):842-4.

30. Vroman DT, Hutchinson AK, Saunders RA, Wilson ME. Two-muscle surgery for congenital esotropia: rate of reoperation in patients with small versus large angles of deviation. J AAPOS. 2000;4(5):267-70.

31. Prieto-Díaz J, Souza-Dias C. Esotropias. In: Prieto-Díaz, Souza-Dias C (eds). Estrabismo. São Paulo: Livraria Santos Editora; 2002. p.14999 .

32. Bracamontes AC. Manejo Quirúrgico de la Exotropia Secundaria. In: XII Congreso del Consejo Latinoamericano de Estrabismo; Buenos Aires, 1996:173.

33. Carvalho KM, Millán T, Minguini N, Wakamatsu TH. Peribulbar versus General Anesthesia for Horizontal Strabismus Surgery. Arq Bras Oftalmol. 2008;78(3):352-6.

34. Wakamatsu TH, Millán T, Minguini N, Carvalho, KM. Correção de estrabismo sob anestesia peribulbar. Arq Bras Oftalmol. 2004;67 (suppl 4):74.

35. Hamilton RC. Complications of ophthalmic regional anesthesia. Ophthalmol Clin North Am. 1998;11:99-114.

36. Davis DU, Mandel MR. Efficacy and complication rate of 16224 consecutive peribulbar blocks: a prospective multicenter study. J Cataract Refract Surg. 1994;20:327-37. 